\title{
Caries en niños. iMaltrato infantil o ignorancia parental?
}

\author{
Carries in children. Child abuse or parental igmorance?
}

\author{
Agustín Tiol-Carrillo*
}

\section{RESUMEN}

El maltrato infantil es un tema polémico en la actualidad, y se caracteriza por realizar acciones u omisiones intencionales destinadas a menoscabar o afectar la integridad física y/o psicológica de un menor. Frecuentemente se considera a la caries en niños como un indicador objetivo de maltrato infantil. La caries es una enfermedad extremadamente común en la población infantil en México y en el mundo, por lo que su relación con el maltrato infantil carece de un sustento real. El desarrollo de caries en niños no es un evento premeditado ni intencional, es más bien la consecuencia de malos hábitos higiénicos y dietéticos que el odontólogo tiene la obligación de corregir y erradicar para asistir a los pacientes pediátricos a recuperar su salud bucodental. El objetivo del presente artículo es debatir la relación entre la caries temprana de la infancia y el maltrato infantil.

Palabras clave: Caries temprana de la infancia, maltrato infantil, caries en niños.

\section{ABSTRACT}

Child abuse is currently a controversial issue and is characterized by intentional actions or omissions intended to undermine the physical and/or psychological integrity of a minor. Caries in children is often considered an objective indicator of child abuse. Caries is an extremely common disease in the child population in Mexico and in the world, so its relationship with child abuse lacks any real support. The development of cavities in children is not a premeditated or intentional event, it is rather the consequence of poor hygienic and dietary habits that the dentist has the obligation to correct and eradicate in order to assist pediatric patients to regain their oral health. The aim of this article is to discuss the relationship between early childhood caries and child abuse.

Keywords: Early childhood caries, child abuse, caries in children.

\section{INTRODUCCIÓN}

$\mathrm{L}$ a caries dental es una de las enfermedades más $\rightarrow$ comunes en todo el mundo, y en México es considerada como un problema de salud pública por su alta prevalencia. Se estima que de 60 a 90\% de la población preescolar y escolar padece o ha padecido caries. ${ }^{1}$

La etiología de la caries es bien conocida, se sabe que para que ésta se desarrolle es necesaria la interacción simultánea de diferentes elementos como agentes propios del huésped (como la cantidad y calidad del flujo salival), sustratos de la dieta y agentes microbianos capaces de producir ácidos y enzimas proteolíticas. ${ }^{2}$ Todos los factores anteriormente mencionados interactuando por tiempo suficiente son necesarios para producir daño a la estructura dental. ${ }^{1}$

Los factores necesarios para su aparición son múltiples, pero además de su etiología local, existen otros factores determinantes para su desarrollo, entre los que destacan el bajo nivel educativo y socioeconómico, la ausencia de hábitos higiénicos y la falta de accesibilidad a los servicios de salud. ${ }^{3,4}$

En la actualidad, el maltrato infantil es un tema polémico. Por la gravedad inherente a este acto, muchos profesionales de diversas ramas han intentado profundizar en este tópico tan importante, y los odontólogos no han sido la excepción. Sin embargo, en odontología se ha vinculado erróneamente a la caries dental como un

\footnotetext{
* Especialista en Estomatología Pediátrica. Máster en Odontología Legal y Forense. Profesor investigador en UAM Xochimilco, México.

Recibido: 14 de mayo de 2021. Aceptado: 13 de julio de 2021. 
fuerte indicador de maltrato infantil, generando como consecuencia que los odontólogos señalen como maltratadores a los padres de cualquier niño que padece caries sin bases sólidas ni pruebas suficientes que lo sustenten, sin tomar en cuenta que el desarrollo de caries es un proceso patológico crónico multifactorial que poco tiene que ver con actos mal intencionados dirigidos a dañar o menoscabar la integridad de un menor.

El objetivo del presente artículo es debatir la relación existente entre la caries temprana de la infancia con el maltrato infantil.

\section{EL MALTRATO INFANTIL}

Considerado como patología por la Organización Mundial de la Salud (OMS) desde 1999, se conoce como maltrato infantil a la violencia contra los menores y sus respectivas consecuencias físicas y emocionales que sufre la víctima.

El maltrato infantil puede presentarse en una gran gama de modalidades, desde el abuso físico, el abuso sexual, el abuso psicológico o la negligencia, por lo que los indicadores para el diagnóstico de esta problemática van más allá de lo imaginable. Resulta interesante notar que la Clínica de Atención Integral al Niño Maltratado (CAINM) del Instituto Nacional de Pediatría, diseñada para detectar y tratar los casos de maltrato infantil, sustenta que sólo $10 \%$ de la población pediátrica puede en realidad ser víctima de algún tipo de maltrato. ${ }^{5}$

La CAINM define al maltrato infantil como cualquier agresión u omisión intencional ya sea física, sexual, psicológica o negligente, dentro o fuera del hogar, contra una persona menor de edad, antes o después de nacer, que afecte a su integridad biopsicosocial, realizada habitual u ocasionalmente por una persona, institución o sociedad, en función de su superioridad física, intelectual o económica.

Como se podrá notar en el párrafo anterior, el maltrato se caracteriza por ser intencional, es decir, con el pleno entendimiento y deseo de lastimar o vulnerar la integridad de un menor.

Resulta relevante destacar que, en muchos casos, el maltrato no es ejecutado directamente por los padres del menor, sino por personas ajenas al vínculo familiar. ${ }^{6}$ De acuerdo con investigaciones sobre maltrato infantil, los agresores más comunes en orden de frecuencia son el padrastro, la nana y por último, el padre o la madre. ${ }^{6,7}$

De acuerdo con la literatura actual, son múltiples los indicadores de maltrato infantil, la mayoría de ellos pueden ser manifestaciones puramente cutáneas, como hematomas, contusiones, laceraciones en diferentes eta- pas de curación, con incongruencia en el mecanismo de su producción, y a la anamnesis con diversas versiones de los hechos por parte de los cuidadores; ${ }^{6}$ sin embargo, muchos otros indicadores de maltrato psicológico o sexual pueden ser no valorables clínicamente, y no es competencia del odontólogo analizarlos.

Así pues, la caries temprana de la infancia ies en realidad un signo objetivo de maltrato infantil? Para poder comprender mejor la respuesta a esta interrogante primero es necesario considerar cuántos niños en México padecen o han padecido caries, y a su vez cuestionarnos si todos estos niños, por el sólo hecho de padecerla, son maltratados o no. Cabe destacar que es imposible asegurar que un niño sin caries no pueda ser víctima de maltrato infantil.

La caries es un problema de salud pública a nivel mundial y es considerada como la enfermedad crónica más común en la población infantil. ${ }^{8}$ Por tanto, al tratarse de una enfermedad tan prevalente en el mundo y por su etiología multifactorial, su relación con el maltrato infantil es en realidad una falacia.

Son muchos los factores necesarios para el desarrollo de la caries dental, dentro de los más importantes destacan la mala higiene oral y una dieta rica en carbohidratos, y es una realidad que los hábitos de higiene bucodental en México son considerablemente deficientes, ya que muchos pacientes desconocen la forma correcta de realizar el cepillado dental, ignorando a su vez la relevancia de la higiene bucodental y los aditamentos disponibles para realizarla adecuadamente. Aunado a lo anterior, los hábitos dietéticos de los niños en México son cuestionables, el consumo de alimentos no nutritivos predispone a la población infantil a desarrollar obesidad y caries dental, o bien a incubar hábitos nocivos que desencadenen enfermedades crónico-degenerativas en la edad adulta (como diabetes, hipertensión o enfermedades cardiovasculares).

Los hábitos alimentarios son influenciados por factores biológicos, ambientales y socioculturales, ${ }^{9}$ donde numerosas familias no cuentan con los recursos económicos suficientes para proveer una dieta saludable y balanceada a todos los miembros de la familia y la fácil disponibilidad de adquirir alimentos no nutritivos a un menor costo son factores que se deben tomar fuertemente en cuenta.

\section{DISCUSIÓN}

El que suscribe, odontólogo pediatra de profesión, debate la idea de que la caries en niños sea un indicador objetivo de maltrato infantil. Lo anterior debido a que, como ya se mencionó con antelación, la caries es una enfermedad 
cuya prevalencia global es extremadamente alta tanto en la adultez como en la infancia.

En la mayoría de las ocasiones, los padres o cuidadores del niño son en realidad quienes padecen caries y la perniciosa microbiota oral (con abundantes cantidades de Streptococcus mutans y Lactobacillus) de los padres puede transmitirse al niño por contacto directo e íntimo o al compartir utensilios durante la alimentación. ${ }^{10}$ Aunado a lo anterior, una dieta rica en carbohidratos y una deficiente higiene oral predispone al niño a desarrollar caries.

La ignorancia de los padres frente a la etiopatogenia de la caries temprana de la infancia es el verdadero problema y los odontólogos estamos obligados a educar y concientizar a los pacientes y a sus familiares/cuidadores sobre la importancia de las técnicas de prevención, e implementar buenos hábitos higiénicos y dietéticos para evitar el desarrollo de lesiones cariosas, fuera de juzgar o acusar como maltratador al padre de un menor que acude a consulta para buscar atención dental para su hijo.

El odontopediatra se enfrenta diariamente a falsas creencias que evidencian la ignorancia de los padres frente a la salud bucal de su hijo, argumentando erróneamente que los dientes del menor están dañados por la ingesta de determinados fármacos o por algún defecto del desarrollo dental, o más grave aún, la peligrosa creencia de que los dientes primarios no son relevantes por su temporal permanencia en la boca, por lo que su mantenimiento y rehabilitación no son necesarios.

Por tanto, el odontólogo, así como cualquier otro profesional de la salud, además de tener conocimientos teóricos y prácticos que permitan resolver las patologías de los pacientes, deben fungir como promotores de la salud, fomentando en todo momento la educación para la salud, que, de conformidad con la 36 a ${ }^{\text {a }}$ Asamblea Mundial de la Salud, es el conjunto de actividades de información y educación que permite a las personas alcanzar niveles de salud óptimos, teniendo como principal objetivo modificar creencias, costumbres y hábitos no saludables.9,11,12

La mayoría de los padres que acuden al odontopediatra se encuentran preocupados por la salud bucal de su hijo y buscan asistencia profesional para resolver dicha problemática a pesar del alto costo que el tratamiento pudiera tener. Al inicio de todo tratamiento odontológico resulta imprescindible identificar los factores que llevaron al niño a desarrollar caries y modificarlos a la brevedad para evitar la aparición de nuevas lesiones, informando a los padres del menor de la forma más completa y explícita posible las medidas preventivas, higiénicas y dietéticas disponibles para tratar de forma individualizada el padecimiento del niño, creándose así un mutuo compromiso y responsabilidad por parte del paciente, sus padres y el odontopediatra.

Por tanto, por su etiología multifactorial, la cronicidad de su evolución y su alta prevalencia resulta inaudito vincular a la caries con maltrato infantil, ya que el maltrato es una condición intencional encaminada a afectar, lastimar o menoscabar la integridad física y/o psicológica del menor, y es irracional creer que los padres de un niño, por voluntad propia, decidan no realizar la higiene oral esperando que en algún momento los dientes de su hijo se dañen.

Por otro lado, resulta inquietante asegurar que todos los niños que acuden a la consulta de odontopediatría buscando atención dental por padecer caries sean niños maltratados, y más aún, creer que el odontólogo tenga la capacidad de determinar quiénes de sus pacientes son maltratados y quiénes no basándose exclusivamente en el estado bucodental de cada uno, sin tomar en cuenta los factores de riesgo intrínsecos del paciente, el nivel educativo y socioeconómico de los padres, así como los hábitos higiénicos y dietéticos del niño.

Es alarmante la seguridad con la que numerosos estomatólogos acusan a los padres como maltratadores, incluso creyendo erróneamente que tienen la autonomía para denunciar maltrato ante alguna autoridad competente sin tener elementos suficientes que permitan constatar lo anterior, lo cual puede incurrir en calumnia o difamación.

\section{CONCLUSIÓN}

La caries es considerada como la enfermedad crónica más prevalente durante la infancia, por lo que su relación con el maltrato infantil carece de sustento, debido a que el maltrato infantil es siempre intencional y se ejecuta deseando lastimar o afectar a un menor, por lo que resulta absurdo creer que los padres llevarán a cabo acciones intencionales destinadas a afectar la salud bucal de su hijo.

La caries temprana de la infancia es en realidad la consecuencia de un conjunto de elementos que interactúan simultáneamente como la ignorancia por parte de los padres o cuidadores, el nivel socioeconómico familiar que indirectamente conllevan a malos hábitos dietéticos y deficiente higiene oral. No debemos olvidar que la función del odontopediatra fuera de juzgar o acusar a los padres de un niño como maltratadores consiste en educar a los padres, enseñando detalladamente los aditamentos existentes para realizar adecuadamente la higiene bucodental y las medidas preventivas en casa y a nivel profesional destinadas a evitar el desarrollo de nuevas lesiones. 


\section{REFERENCIAS}

1. Vera HH, Valero PMGY, Reyes NA, Luengas QE. Niñas y niños libres de caries en México. Revista ADM. 2010; 67 (5): 217-222.

2. Higashida B. Odontología preventiva. México, D.F.: McGraw Hill. 2009.

3. Hernández-Cantú EI, Reyes-Silva AKS, García-Pineda MA, González-Montalvo A, Sada-Amaya LJ. Hábitos de higiene bucal y caries dental en escolares de primer año de tres escuelas públicas. Rev Enferm IMSS. 2018; 26 (3): 179-185.

4. Pantoja- Tamayo O. Influencia de la lactancia materna sobre la aparición de maloclusiones en escolares de 5 a 6 años. MEDISAN. 2014; 18 (8): 1091-1098.

5. Loredo AA, Monroy LDA, Casas MA. El maltrato infantil. Conceptos básicos de una patología médico social legal. Rev Fac Med la UNAM. 2013; 56 (6): 5-10.

6. Palacios-López C, Durán-McKinster C, Orozco-Covarrubias L, Saéz-De Ocariz M, Ruiz-Maldonado R. Maltrato infantil en México. Dermatol Rev Mex. 2016; 60 (4): 326-333.

7. Pau-Charles I, Darwich-Soliva E, Grimalt R. Signos cutáneos de maltrato infantil. Actas Dermosifilogr. 2012; 103 (2): 94-99.

8. Abuaisha AA, Huda BZ. Oral hygiene habits and its association with dental caries among children aged 8-12 years in Libyan Schools,
Klang Valley, Malaysia. International Journal of Public Health and Clinical Sciences. 2016; 3: 44-58.

9. Macias MAI, Gordillo SLG. Camacho REJ. Hábitos alimentarios de niños en edad escolar y el papel de la educación para la salud. Rev Chil Nutr. 2012; 39 (3): 40-43.

10. Rojas FS, Echeverría LS. Caries temprana de la infancia: ¿enfermedad infecciosa? Rev Med Clin Condes. 2014; 25 (3): 581-587.

11. Perea QR, Bouche PH. Educación para la salud: reto de nuestro tiempo. Díaz Santos, España, 2004.

12. Valdez I, Villaseñor M, Alfaro N. Educación para la Salud: la importancia del concepto. Rev Educ Des. 2004; 33: 43-48.

Correspondencia:

Agustín Tiol-Carrillo

E-mail: agustintiolcarrillo@gmail.com

Conflicto de intereses: No se tiene ningún conflicto de intereses.

Financiamiento: Ninguno. 